\title{
De la palabra a la imagen: las versiones cinematográficas de $A$ esmorga*
}

Fecha de recepción: : 20 de julio de 2020

Fecha de aprobación: 19 de septiembre de 2021

\section{Resumen}

El propósito de este artículo es realizar una comparación entre la obra literaria de Eduardo Blanco Amor, A esmorga, y los filmes Parranda, del director Gonzalo Suárez, y A esmor$g a$, del cineasta Ignacio Vilar. Se intenta realizar un ejercicio de literatura comparada, donde la metodología predominante es la empleada en el estudio de las relaciones interartísticas, más concretamente entre la literatura y el cine. Para realizar el análisis comparativo, se estudia elementos como el tiempo, el espacio, narradores, los personajes, la crítica cinematográfica, entre otros. Finalmente, los resultados encontrados son dispares, muy significativos en dichas películas, aunque la esencia siga siendo la misma, debido a la influencia del hipotexto.

Palabras clave: A esmorga, cine, Eduardo Blanco Amor, literatura, literatura comparada.

Citar: Puime Sabugueiro, Montserrat. "De la palabra a la imagen: las versiones cinematográficas de A esmorga". La Palabra, num.40, 2021, e13220. (연 https://doi.org/10.19053/01218530.n40.2021.13220

\section{Montserrat Puime Sabugueiro}

Investigadora en la Universidad de Vigo. Área de Teoría de la literatura y Literatura Comparada. montse.p.s@edu.xunta.gal iDhttps://orcid.org/0000-00026785-5092

* Artículo de reflexión. 


\title{
A smorga: From the novel to the cinema
}

\begin{abstract}
The novel by Eduardo Blanco Amor written in Galician language $A$ smorga is compared in this paper to the films Parranda by Gonzalo Suárez and $A$ smorga by Ignacio Vilar. Interartistic methodology is arranged here due to the possibility from Comparative Literature which allows the study of different artistic assessments -in this case literature and cinema. In such a way, it is analysed space-time, the teller, characters, movies critics, and so on. The findings reveal remarkable differences between cinema and literature in this works. It is concluded also that the base text of the novel is preserved in some way.
\end{abstract}

Key words: A smorga, cinema, Eduardo Blanco Amor, literatura, Comparative Literature.

\section{Da palavra à imagem: as versões cinematográficas de A esmorga}

\section{Resumo}

O propósito deste artigo é desenvolver uma comparação entre a obra literária de Eduardo Blanco Amor, A esmorga, e os filmes Parranda, do diretor Gonzalo Suárez, e A esmorga, do cineasta Ignacio Vilar. Procura-se realizar um exercício de literatura comparada, no qual a metodologia principal é a utilizada no estudo das relações interartísticas, mais exatamente entre a literatura e o cinema. Para a análise comparatista são estudados elementos como o tempo, o espaço, os narradores, as personagens, a crítica cinematográfica, dentre outros. Por fim, os resultados obtidos são díspares, muito significativos nos filmes, embora a essência seja a mesma, devido à influência do hipotexto.

Palavras-chave: A esmorga, cinema, Eduardo Blanco Amor, literatura, literatura comparada. 
A esmorga, novela de Eduardo Blanco Amor publicada en Buenos Aires en $1959^{1}$ y escrita en gallego, es, a juicio de los especialistas, la obra inaugural del período contemporáneo de la narrativa gallega, o, como afirma Manuel Forcadela, "sinala un fito histórico na nosa narrativa" (6). El éxito de su acogida por la crítica y los lectores se evidencia en el importante número de traducciones a diversas lenguas (castellano, italiano, francés, japonés, catalán, entre otros) y en las adaptaciones al teatro y el cine. El propósito de este artículo es analizar los discursos cinematográficos basados en esta novela; se está aludiendo a La Parranda, película dirigida por Gonzalo Suárez en 1977, y A esmorga, dirigida por Ignacio Vilar en 2014.

A esmorga, la novela, está dividida en dos partes. En la primera, muy corta y a modo de prólogo, titulada "Documentación", una voz, que podemos identificar con la del autor, explica el proceso de documentación seguido para conocer todos los datos posibles de un suceso real que las gentes del pueblo recuerdan; la segunda, conformada por cinco capítulos de desigual duración, contiene ese suceso en la voz de Cibrán ${ }^{2}$ — protagonista y narrador - sometido a interrogatorio en un acto judicial. Las respuestas de Cibrán a las preguntas de un juez, cuya voz se silencia, refieren la juerga vivida en un fin de semana por tres hombres: Bocas ${ }^{3}$, Milhomes $^{4}$ y él mismo, en la ciudad de Auria (traslación literaria de Ourense). Las pulsiones de los personajes funcionan como desencadenantes de la acción. Cibrán, debido a su débil carácter, a su incertidumbre existencial (que él denomina pensamento), se deja llevar por la historia y el tiempo. Milhomes es un homosexual enamorado de Bocas, propenso a la broma y a los excesos con el alcohol; y Bocas es un hombre que quiere reforzar su masculinidad, tendente a la depresión y obsesionado con una hermosa mujer que dice haber visto, la señora del pazo de Andrade. La debilidad de uno y los primitivos e irracionales instintos de los otros, reforzados por el alcohol, les conducirán trágicamente a la muerte. Milhomes mata a Bocas en un ataque de furia, provocado por los celos, y después muere intentando escapar de la benemérita. Cibrán es capturado por los guardias y termina confesando lo sucedido, después, muere por causas desconocidas, aunque el autor refleja dos posibles finales: suicidio, utilizando el mismo cuchillo con el que Milhomes había matado a Bocas, o muerte a consecuencia del maltrato recibido por parte de sus captores ${ }^{5}$.

La novela, de un crudo y radical realismo ${ }^{6}$, ofrece al comentarista numerosos temas para el análisis que han sido abordados por voces acreditadas, algunas de las cuales figuran en la bibliografía final. Pero nuestro trabajo se inscribe en el ámbito de la literatura comparada y, más concretamente, en el estudio de las relaciones interartísticas entre dos películas basadas

Aunque su escritura es unos años anterior a la fecha de publicación. De hecho, Blanco Amor terminó de escribirla en 1955, si nos atenemos a la fecha que figura en el manuscrito de $A$ Esmorga depositado para la censura: "Bs. Ares, 25 de maio a 8 de outono de 1955", como indica Xosé Manuel Dasilva Fernández (40). La primera edición en español, titulada La parranda y traducida por el propio autor, se publica también en Buenos Aires en 1960. La primera edición en España verá la luz en la Editorial Galaxia en 1970.

2 Cipriano Canedo, conocido por Cibrán y apodado "Castizo".

3 Juan Fariña, apodado "Alifante" y también "Peitodemacho", es el líder del grupo y un hombre de gran corpulencia y mal carácter. Mantiene con Milhomes una muy profunda y estrecha amistad.

4 Su nombre es Eladio Vilarchao y se le conoce por Milhomes, "Papaganduxos" o por "Maricallas".

5 "Anque endexamais quedou craro, entre a xente do pobo, se morreu da navallada ou dos culatazos con que alí mesmo o mallou a parexa da Benemérita" (p. 115).

6 También, esta novela se le inscribe al tremendismo género literario que se desarrolla en España alrededor de la década de 1940. La novela de Cela, La familia de Pascual Duarte (1940), es considerada la iniciadora de este género. 
en el mismo hipotexto: la novela de Blanco Amor. Por ello, dada la amplitud del objeto de estudio, centraremos nuestra atención en algunos de los elementos que nos han parecido de mayor interés.

A nuestro juicio uno de los ejes estructurales más destacados en la obra de Blanco Amor es el tratamiento del tiempo, aspecto que Xosé Luís Gavilanes Laso detalla del siguiente modo:

no tocante á caracterización temporal, a novela presenta dous tempos: un presente central, cuia unidade se axusta ao pseudodiálogo entre o narrador e o xuez, e un tempo pasado cronolóxico, cuia unidade se axusta aos feitos propiamente ditos que, no decurso de vintecatro horas, constitúen toda a sarta de peripecias que contén a anécdota. O presente central interfírese frecuentemente no pasado cronolóxico a traveso de sucesivos cortes dados a requerimento do interrogador. (287)

Si la historia narrada, dejando al margen lo que podemos llamar "Prólogo" (capítulo 1) y "Epílogo" (final del capítulo 5), es la declaración de un procesado ante un juez, es evidente que el discurso literario se mueve en dos tiempos: el presente de la declaración y el pasado en el que ocurrieron los hechos que el reo declara. La técnica utilizada por el autor es el pseudodiálogo o diálogo callado, es decir, el lector solo tiene acceso a la voz de uno de los interlocutores, en tanto que, la voz del otro se silencia y ha de ser deducida en función de la respuesta dada. En A esmorga, el lector conoce las respuestas del acusado, Cibrán, y de ellas infiere las preguntas del juez, preguntas que se omiten y formalmente se marcan en el texto con guiones.

Es cierto que el lector no dispone de datos suficientes para situar la historia en una época determinada y, a pesar de que en el capítulo "Documentación" se dice explícitamente que los hechos narrados ocurrieron noventa años antes de la publicación ("púxenme agora a escribir esta crónica, a coasi corenta anos de tere recollida tan lene documentación e a noventa dos sucesos mesmos") ${ }^{7}$, por lo que tendríamos que emplazar tales sucesos en 1869; sin embargo, ese dato no es del todo fiable, ya que, como demuestran algunos estudiosos, la obra presenta incongruencias o errores en determinados comentarios o fechas:

Refírese Cibrán á Ponte Nova, unha das catro que hoxe en Ourense, atravesa o río Miño, construída entre os anos 1911 e 1918. Da inminente visita do deputado deducimos que as obras estarían próximas ó seu remate, e cerca, por tanto, da última data mencionada. Outros datos confirman esta ambientación, como a alusión, no pasado recente, a unha viaxe de - El Rei (Afonso XIII visitou Ourense en 1904 e 1907). (Unha lectura 39)

Pero, no podemos descartar la hipótesis de que se trate de falsos errores o, otra manera expresarlo, que Blanco Amor los hubiera cometido de manera deliberada con el propósito de impedir una ubicación temporal concreta. Recordemos, además, que estamos en el territorio

Cito la novela por la $3^{\mathrm{a}}$ edición publicada por Galaxia en 2010. La cita en la página 11. 
de la ficción, por consiguiente, y a pesar de la clara intencionalidad realista de la novela ${ }^{8}$, delatada también por la utilización de la palabra "crónica" " "púxenme agora a escribir esta crónica,..."), el autor es libre de trasladar en el tiempo cualquier anécdota, lugar o mención que incorpore a su relato.

Si analizamos cómo es presentado el marco espacio-temporal en las dos adaptaciones cinematográficas que aquí ocupan el interés, se puede comprobar una primera diferencia, y no menor, entre ambos filmes:

La película de Ignacio Vilar, A esmorga, sitúa la historia en la década de 1950; no se especifica con exactitud el año en que suceden los hechos, pero, como dice Álvarez Patiño, "se deja claro a través del filme que nos encontramos en la etapa franquista del país, al afirmarse que vendría el caudillo para inaugurar una presa" (15). Por el contrario, en la versión de Gonzalo Suárez, Parranda, el tiempo de la historia es incierto (como en la novela); el discurso fílmico no proporciona elementos suficientes que permitan al espectador anclar la historia a un tiempo y un espacio particular. El resultado es que Gonzalo Suárez no parece tener como finalidad principal mostrar cómo era la vida de la época, de hecho, sus imágenes reflejan cierta modernidad.

Otra cuestión relacionada con el marco temporal de las dos películas revela también diferencias entre una y otra. Cabe recordar que el texto que ambos filmes adaptan, contiene tres marcos temporales: el primero nos sitúa en el presente del narrador-autor; el segundo, en el presente del narrador-enunciador; y el tercero, en el pasado del narrador-protagonista. Pues bien, Gonzalo Suárez mantiene dos de esos marcos: el pasado que recuerda y cuenta Cibrán, flashback que constituye el cuerpo de la película, y el presente de la declaración al principio y al final con los primeros planos sobre el rostro de Cibrán, que le muestran todavía más ingenuo y frágil. Por su parte, Ignacio Vilar encierra su discurso fílmico en un solo marco temporal, que contiene únicamente la historia de la declaración de Cibrán. Esta diferencia afecta, como se verá, a otro de los ejes estructurales de los filmes: la enunciación narrativa.

Por otra parte, en ambas versiones fílmicas hay dilataciones temporales, es decir, el tiempo del discurso es mayor que el tiempo de la historia narrada. Estas dilataciones se consiguen gracias al empleo de técnicas de edición, como el montaje alterno, la cámara lenta, los planos generales (además de los primeros planos), etc.

No es infrecuente en las obras de autores gallegos que sitúen sus ficciones en la ciudad de Ourense. Podríamos citar a Vicente Risco, Otero Pedrayo, Méndez Ferrín, Carlos Casares, Curros Enríquez, entre otros. Quizás, la razón por la que emplean esta localización geográfica estribe simplemente en que es la cuna de muchos de ellos. También el espacio de A esmorga es Auria (trasunto ficcional de Ourense). El propio Blanco Amor, en su guion cinematográfi-

En su Guía de lectura de la novela, Manuel Forcadela expone: “A Esmorga de Eduardo Blanco Amor debemos ubicala dentro dos resultados que a perspectiva crítica creada pola socioloxía vai ter no mundo da creación literaria e, fundamentalmente, vencellada a un movemento artístico de posguerra que coñecemos co nome de neo-realismo. O movemento, como ben pode desprenderse do seu propio nome, trátase dun esforzo por encontrar un modo realista de narrar adecuado á expresión dos novos tempos" (12). 
co de Parranda, aclara la razón por la que elige ese lugar: "Se sugiere que los exteriores sean rodados en Orense; no porque el autor sea de allí, sino por el excepcional carácter escenográfico, en lo popular, que tiene su barrio viejo" (La Parranda e outros guións 36).

Veamos ahora cuál es la localización espacial en las películas que se analiza y el por qué existe una clara diferencia entre las dos propuestas cinematográficas.

Parranda está rodada, en su mayor parte, en Asturias. Tal vez, la causa fue una imposición de la productora, por razones económicas, como sugiere el siguiente fragmento de una carta de Gonzalo Suárez a Blanco Amor, con fecha de diecinueve de agosto de 1976, en la que el cineasta se lamenta de la nueva localización del filme: "Para empezar, no es una decisión que yo tomé (por tanto no sentí en ningún momento la necesidad de la traslación) sino que me fue impuesta, y lo que yo hice [...] fue asimilar a posteriori y no oponerme al inesperado cambio de lugar"9. Pero un visionado atento de la película de Suárez admite barajar otras conjeturas: la primera, y la más simple, pero que no debemos obviar, es que el director nació en Asturias y, como todos los amantes del cine saben, muchas de sus películas tienen ese mismo escenario. Pero cabe todavía otra conjetura más, y de mayor calado, se alude a la posibilidad de que el cineasta pretendiera mostrar que esa historia podría suceder en cualquier lugar; y si hablamos de conjetura y no de hipótesis es porque nos apoyamos en el tratamiento de la temporalidad en este discurso filmico, que se acaba de examinar: un tiempo impreciso, indeterminado, un espacio cualquiera...

Nada de esto sucede en la película de Ignacio Vilar, A esmorga, rodada íntegramente en Galicia, y en gallego, pone gran énfasis en los espacios rurales y en algunas zonas típicas de Ourense, sobre todo del casco vello (la Catedral, la fuente de Santo Tomé, la Plaza Mayor, etc.), como era de esperar en una adaptación fiel al texto literario. En el discurso fílmico abundan los planos secuencia, construidos con diversas escalas de planos y con movimiento de cámara en travelling, técnicas que permiten al espectador seguir el movimiento de los personajes en el espacio, añadiendo realismo y verosimilitud a la acción. La cuidada ambientación y la decoración (primeros planos de instrumentos típicos de cocina, actividades relacionadas con la comida, entre otros) se ponen al servicio de mostrar al espectador el modo de vida en aquellas primeras décadas del franquismo, tanto en los espacios rurales como urbanos. Se advierte, en el cineasta, un interés profundo en mostrar los usos y costumbres de la Galicia rural, o de darle a la naturaleza la relevancia que realmente merece.

Blanco Amor articula la historia a través de dos voces: la voz del narrador-autor y la voz del narrador-protagonista ${ }^{10}$. Estas voces forman parte de dos marcos narrativos situados en el presente y en el pasado, respectivamente. El narrador-autor es el responsable de la enunciación en el presente, a modo de Prólogo, titulado "Documentación", y en los tres últimos párrafos del último capítulo. Para Manuel Forcadela, el hecho de esclarecer que la

Se extrae esta información del bien documentado libro de Ana Belén Martínez Delgado: A esmorga de Blanco Amor e Parranda de Gonzálo Suárez.

10 Dichos términos fueron sacados del estudio realizado por Manuel Forcadela, Guía de lectura de A esmorga de Eduardo

Blanco Amor. 
narración es el resultado de la recogida de información por todo el pueblo y de una investigación a partir de documentos procesales, "contribúe a facernos ver a historia como algo herdado e que forma parte da mítica dunha colectividade á que el mesmo pertence e que lle foi contado por distintas persoas en épocas diferentes" (20). En otro orden de cosas, como acertadamente sostiene este investigador, la utilización de dicho marco narrativo funciona como una captatio benevolentiae ${ }^{11}$ :

un dos moitos recursos (topos) da retórica clásica que consistía xustamente en procurar un acollemento benévolo do discurso por parte do receptor. Repárese, a parte do parágrafo final onde o autor parece asumir as posibles críticas que a súa obra suscite polo xeito en que está escrita. (Guía de lectura 22)

El narrador-protagonista es el responsable de la narración en el segundo marco, el del pasado, que abarca desde el capítulo uno hasta el cinco (con la excepción de los tres fragmentos finales antes mencionados). Teniendo esta estructura en el recuerdo, se va a analizar la perspectiva narrativa en los dos filmes:

En la película de Vilar, A esmorga, el narrador es Cibrán, quien es coprotagonista de toda la historia. Al comienzo de la película y en sucesivas secuencias, a lo largo del discurso fílmico, se insertan fragmentos de la declaración de Cibrán, tanto manteniendo su imagen en el campo de visión como por medio de la banda sonora que nos permite oír su voz fuera de campo, en off. De esta manera, el director gallego suprime en su filme el marco de narrador-autor que contenía la novela que adapta, hecho que, sin duda, simplifica los problemas de producción de la película. Ignoramos cuál fue la razón por la que el realizador decidió emplear este procedimiento, quizás para darle más credibilidad o realismo a la historia contada, o bien, para no tener que añadir un personaje más que dificultase la correcta interpretación del relato a los espectadores. Las palabras del propio Ignacio Vilar para una entrevista en Cinema Ad Hoc ${ }^{12}$ parecen confirmar esta hipótesis:

había una cosa que me interesaba mucho y era la de darle verdad. Verdad en el sentido que pueda tener el documental, verdad que tiene el plano secuencia porque el plano/contraplano es más artificial. Después, A Esmorga es el imaginario de miles de personas en Galicia, cada uno se ha hecho su película en su cabeza al leer la novela, y hacer una película en la que pudieran entrar todas las que cada espectador se hubiera hecho en su mente es impresionante. (Vilar párr. 6)

Con respecto a la película de Gonzalo Suárez, Parranda, la narración de los acontecimientos adquiere mayor complejidad. En este caso se parte, como en el hipotexto, de dos voces enunciadoras: la del narrador-autor y la del narrador-protagonista. Para la primera, el realizador introduce un personaje (inexistente en la novela) el profesor de lenguas clásicas, que conseguirá funcionar como el magistrado. De él, dice José Manuel Sande que es:

\footnotetext{
11 “...será doado que se resinta dalgunhas chatas no tocante á verdade obxetiva, coma decote pasa coas fórmulas realistas ás que este escrito se axusta conscentemente, ademetindo, por adiantado, o seu autor, os normaes aldraxes e vilipendios que de tal declaración poidan seguirse" (p. 11).

12 https://cinemaadhoc.com/2015/05/entrevistas-ignacio-vilar/
} 
Un personaje clave, el presunto profesor de lenguas clásicas, escribiente y juez de instrucción interpretado por Fernando Fernán Gómez, nave nodriza en las relaciones de jerarquía narrativa, se transforma con sus reiteradas interpolaciones en el demiurgo de la historia, un agente en el que confluyen los distintos niveles narrativos. (164)

Suárez traslada la técnica del narrador-autor a su filme gracias a las interpolaciones de este personaje a lo largo de la historia (cuando se encuentran con él y el muerto, cuando se narran los sucesos del asesinato, cuando encuentran la casa de Monfortina, cuando se descubre que es el magistrado, etc.), por medio del él y de la atmósfera de mentiras y sarcasmo que lo rodean, el director lleva a cabo una crítica a la hipocresía de la justicia ${ }^{13}$. Este recurso muestra cómo la "reinterpretación do director, reside nunha focalización do cine-rrador. Unha forma de dirixirmos a visión. Unha lectura (cinemática) que nos plantexa posibilidades diverxentes de interpretar a novela" (Vázquez e Dobarro 159).

Aunque Gonzalo Suárez decide respetar la narración en primera persona que emplea Eduardo Blanco Amor en la novela, en la película no conocemos lo que pasó gracias a la declaración de Cibrán, como testigo delante del juez, sino desde su punto de vista en un flashback, obligado por los golpes de los interrogadores de la Guardia Civil. Como afirma Ana Belén Martínez Delgado, la técnica que emplea el director es la del multiperspectivismo visual, ya que "o proxecto comunicativo da novela vertébrase arredor dun autor implícito nun metanivel, de Cibrán e o do Xuíz nun primeiro nivel e duns enunciadores, que poderiamos denominar secundarios, dependentes en gran parte da entidade enunciativa Cibrán pola falta de autonomía" (46).

Por tanto, en la perspectiva narrativa radica también una de las importantes diferencias que se encontró entre estos dos discursos fílmicos.

Una de las características de la novela de Blanco Amor es la complejidad de sus personajes, hombres y mujeres llenos de matices, asediados por conflictos psicológicos diversos, conformados por un aspecto físico y una personalidad perfectamente diferenciada. ¿Se mantiene esta característica en las películas que se analizaron? Comenzaremos por la comparación con los personajes que construye el filme $A$ esmorga. La película de Ignacio Vilar es una adaptación como ilustración ${ }^{14}$, esto es, la historia contada es fiel a la obra literaria de la que parte, por lo tanto, los personajes retratados en ella son también muy semejantes a sus modelos literarios. La única excepción que no concuerda con el hipotexto (la novela) es la edad de los protagonistas. Mientras que, en la novela, los tres esmorgantes son jóvenes de alrededor de veinte años, en la película parecen hombres de unos cuarenta a cincuenta años. Castizo (Cibrán), encarnado por Miguel de Lira, refleja sus pensamientos en forma de remor-

13 Respecto de este tema, señala José Manuel Sande: "Los malos tratos sufridos en el interrogatorio [por Cibrán] durante sus intermitentes apariciones y el papel siniestro que juegan las autoridades a lo largo del film [...] nos dejan el sinsabor definitivo, la injusticia de la justicia, la burocratización de todo vestigio humano, con un recorrido por los objetos personales de Cibrán y los cuerpos mudos y resignados de la Rajada y su hijo como testimonio de la muerte de un ser querido en un modélico plano final" (165).

14 Seguimos la tipología de las adaptaciones propuesta por José Luis Sánchez Noriega (De la literatura al cine). Se denomina también adaptación literal. 
dimientos de conciencia, provocados por una crisis existencial; al igual que en la novela, sufre dolor físico y psicológico solo aliviado por la esperanza en un futuro incierto, estado que mantiene hasta el final del filme, donde su rostro, en primer plano, revela que es consciente del final de su historia. Bocas, interpretado por Karra Elejalde, encarna, como en la novela, la masculinidad y represión frente a Milhomes, y muestra su obsesión por conocer a la dueña del Pazo de Andrade. Milhomes, personaje que encarna Antonio Durán Morris, presenta los mismos trazos psicológicos y orientación sexual. A nuestro parecer, este último es de los tres protagonistas, el que más sobresale en el discurso fílmico. Al margen de su excelente interpretación (sin desmerecer el notable trabajo de los otros actores), no es disparatado conjeturar que su condición homosexual y su represión frente a la sociedad fuese el motivo por el que el director creyó conveniente subrayar un poco más esta figura; no olvidemos que durante la década del 2000 al 2010 las películas con mensajes reivindicativos de la comunidad LGBT estaban en auge.

Por su parte, el filme de Gonzalo Suárez es una trasposición ${ }^{15}$, se sitúa en un término medio entre la ilustración y la libre interpretación. El espectador identifica los valores y la esencia de la obra adaptada, pero el resultado es autónomo, no depende del hipotexto. No obstante, los protagonistas de Parranda conservan muchos de los rasgos que poseen en la obra de Blanco Amor, aunque no su físico, ya que ninguno de ellos aparenta ser un veinteañero: Cibrán, interpretado por José Sacristán, presenta aspectos discordantes con la novela, su enfermedad mental a la que él llama pensamento se manifiesta en una especie de ataques de epilepsia y en la pérdida de control de sí mismo, cuando esto sucede se refugia en el alcohol; vive atormentado por el oficio de prostituta de su mujer, Raxada, y el futuro de su hijo; además es perfectamente consciente de dónde y cómo va a acabar la desenfrenada aventura con sus amigos de parranda: en el cuartel de la Guardia Civil y en el suicidio. Bocas, encarnado por José Luís Gómez, es, en esta versión, el personaje que más sobresale, con un peso interpretativo mayor que el resto (aunque el trabajo de todos vuelve a ser notable); como en la novela, se pone sospechosamente de relieve su masculinidad y su espíritu animal, pero también su posición ideológica ("Y dale con el trabajo, tú has nacido para esclavo. Mírame a mí, ¿qué le debo al trabajo?"); aunque aparenta ser un hombre fuerte, brutal y sin debilidades, al final, ya agonizante, confiesa su soledad a Cibrán y pide que no lo deje morir solo. El papel de Milhomes, interpretado por Antonio Ferrandis, mantiene bastante semejanza con el personaje de Blanco Amor, aunque se profundiza en su feminidad, muestra una personalidad abierta, con un tono cómico y despreocupado bastante notorio; Milhomes es un hombre solo, sin familia, excluido de la sociedad, probablemente por su condición homosexual; cuando arrastrado por los celos mata a Bocas, el grito con el que pronuncia su nombre antes de morir confirma el amor que sentía por su compañero de parranda.

15 Así define Sánchez Noriega este tipo de adaptación: "la búsqueda de medios específicamente cinematográficos en la construcción de un auténtico texto fílmico que quiere ser fiel al fondo y a la forma de la obra literaria. Se traslada al lenguaje fílmico y a la estética cinematográfica el mundo del autor expresado en esa obra literaria, con sus mismas $-\mathrm{o}$ similares- cualidades estéticas, culturales e ideológicas" (64). 
Las películas fueron recibidas por la crítica y el público de manera desigual. Como veremos, existe una valoración bien distinta respecto al trabajo de Ignacio Vilar y el de Gonzalo Suárez.

A esmorga logró una magnífica acogida en Galicia. En las páginas de cultura de Praza Pública, escriben con entusiasmo:

A Esmorga, que segue acadando unhas cifras de taquilla que todos cualifican de espectacular. En só dez días, con 18 copias exhibidas únicamente en Galicia, a película supera xa os 20 mil espectadores, sendo unha das dez máis vistas en todo o Estado e acadando a segunda mellor recadación por copia. (párra. 2)

El éxito de taquilla se tradujo en la nominación al Premio Goya en la categoría de mejor guion adaptado. Las críticas del público gallego fueron buenas; la mayoría de los espectadores encomiaban su fidelidad a la novela. Esta similitud con el hipotexto, ligada a un sentimiento nacionalista, y sumada a la utilización de elementos tan gallegos como la lluvia, la ambientación en la época franquista, el uso del idioma, etc., influyeron, sin duda, en el importante éxito de recepción.

Fuera de Galicia, las críticas sobre este filme siguen, en general, con igual tendencia. Por ejemplo, en La Vanguardia, Lluis Bonet destaca sus "imágenes de enorme convicción y notable diseño. El filme supone un hallazgo en estos tiempos de rutina visual y temática" (párr. 4). En el blog Sensacine, Carlos Reviriego valora la obra por contraste con Parranda: "La novela de Eduardo Blanco Amor por fin encuentra en el espejo del cine una obra a su altura, que la hace justicia" (párr. 2), o lo que es lo mismo, considera que la película de Gonzalo Suárez, no está a la altura. El mismo crítico, en un artículo publicado en la revista Caimán Cuadernos de Cine, afirma:

...en el mapa de producción gallega, cinematografía que desde hace unos años viene entregando sólidas y audaces propuestas que generalmente negocian con espíritu documental el retrato de entornos rurales y los ecos arcanos de su civilización. A este respecto, A Esmorga, de Ignacio Vilar, no es una excepción. [...] Película absorbente y desgarradora, el descenso a los infiernos que propone está rodado con determinación naturalista, privilegiando unas interpretaciones extraordinariamente físicas (soberbios los trabajos de Miguel de Lira, Karra Elejalde y Antonio Durán 'Morris') y un ritmo que nos embauca en la experiencia de tránsito de los protagonistas, invitándonos a habitar los espacios que ocupan y atraviesan, pues el entorno por el que transitan se revela igualmente determinante en la psicología del relato. (Reviriego párrs. 1, 3)

En algún caso, la película obtiene alabanzas y reproches, estos últimos casi siempre mencionan la banda sonora musical, aunque también censuran tímidamente otros aspectos. Veamos, por ejemplo, la recensión publicada en Cinema Ad Hoc:

El cineasta gallego Ignacio Vilar ha sido el valiente que se ha atrevido a llevarla [la compleja novela de Blanco Amor] a la pantalla respetando su esencia hasta el más mínimo detalle con todo lo que eso conlleva, para bien y para mal [...] una película cuyo diseño de producción, su puesta en escena y su empeño por el detalle de las descripciones que aparecen reflejadas 
en la novela, crean la atmósfera adecuada para la historia que se está contando. Sin embargo la densidad y reiteración de dicha historia, ayudada por una banda sonora también demasiado redundante, van pesando hasta el punto de hacer difícil mantener el interés en varios momentos de la película. (párr. 1, 4)

Por su parte, la película de Gonzalo Suárez, Parranda, no tuvo mucho éxito comercial. En Galicia, las críticas recibidas, algunas fundamentadas probablemente en prejuicios, fueron bastante duras. El hecho de que la película fuera rodada en tierras asturianas, que no empleara la lengua gallega y que no respetara (entendiendo respeto como adaptación literal) la obra original fue condenado por no pocos críticos. La autonomía del texto cinematográfico respecto a la novela del escritor gallego fue considerada como una ofensa a su nación y también al propio Eduardo Blanco Amor; estas críticas obviaron el hecho de que el autor fuera coguionista de la película, o, cuando menos, colaborador con Suárez en la escritura de ese guion, como rezan los rótulos de los créditos que preceden a la película. Por tanto, Blanco Amor era perfectamente consciente de los cambios introducidos y, hasta donde sabemos, no se opuso a dichos cambios.

Así, Carlos Serantes, en su recensión para la revista A Nosa Terra, defiende que la película obvia muchos aspectos de la idiosincrasia gallega, convirtiéndose en lo que él denomina un "atentado" contra la cultura gallega:

“La Parranda" é a utilización dunha gran novela como anécdota, aínda enriba sin ser respetada nin siquera a este nivel, xa que os pegotes disfuncionáis, son evidentes. Consiste nun atentado contra do mellar espoñente que sobre do lumpemproletariado galego, a súa moral e a súa conduta, nos tén ofrecido a nosa literatura. [...] O xogo de consciente e inconsciente era outra das realidades que desvelaba a novela. Pero nada foi trasladado á película: nin o ambiente nin a atmósfera afogantes, nin o seu forte determinismo social, nin a espresividade sintética da mesma. (citado por Vásquez y Dobarro 150)

Con argumentos similares se refiere a la película Álvarez Pousa, quien defiende que no se puede percibir la atmósfera gallega en el filme y que los personajes principales distan mucho de los originales esmorgantes:

¿Qué quedóu diles, Eduardo? Porque eu non recoñezo, coido que ti menos, ó Cibrán nise epiléptico, nin ó Milhomes nise golfante, nin ó Bocas nise chulo e nugallán. Na extraordinaria autodefensa que fai o Cibrán diante do xuez a quen o autor privou-castigóu sen voz nin palabra, existe unha clara conciencia da súa dinidade persoal, e mesmo da súa condición social, e toda a traxedia pasa pala mesa (que imaxinamos) do xuez coma producto dun mal fado, dunha forza invisíbel que exercite o "pensamento" (racional maneira a de Cibrán de entender o irracional). (citado por Vásquez y Dobarro 19-23)

Ante tales valoraciones, tal vez fuera necesario reflexionar sobre estas palabras de Eduardo Blanco Amor sobre el filme:

"La Parranda" [...] responde en realidade ao confrontamiento de dous guións, un meu e outro do director. Son dúas visións distintas e unha terceira realidade, que é a película mesma, que 
é tanto máis película canto máis deixa de ser novela. Con todos eses filtros, a obra se deslocaliza na mesma medida en que se vai universalizando. Quizá aos galegos non lles pareza ben, desde o punto de vista desa cousa equívoca e tremenda que é o localismo, que pode chegar a ser distinto e ata contrario do galleguismo (Rus Gascón, 1997: 50)

Por el contrario, fuera de Galicia las reseñas sobre la película de Suárez, destacaron su originalidad y su estética marcada. Luis Gómez Mesa se detiene sobre todo en la calidad de la interpretación actoral:

Esos tipos - exagerados, desmadrados- reclamaban unos grandes actores para entenderlos en su vulgaridad tristemente humana y luego encarnarlos en sus excesos, estén o no borrachos. Así lo hicieron José Luis Gómez, Antonio Ferrandis y José Sacristán. Sus actuaciones constituyen toda la película [...] Gonzalo Suárez ha realizado su mejor película. (citado por Vásquez y Dobarro 56-57)

Carlos F. Herrero insiste en la incuestionable estética propia de Gonzalo Suárez que presenta la película, aunque censura algunos de los recursos empleados por el director:

"Parranda" es a todas luces un producto inequívocamente propio de su autor [...] Estamos ante una obra, para mí fascinante, pero no exenta de errores. El primero de ellos, el recurso al ralentí, mediatizando mecánicamente unas secuencias que deberían surgir desde dentro en vez de aparecer impuestas desde fuera... (citado por Vásquez y Dobarro 24)

En suma, y dejando a un lado gustos personales que, a nuestro parecer, pueden enturbiar o adulterar el análisis, estamos ante dos magníficas películas que evidencian dos propósitos y estéticas diferentes. Resultado de fórmulas de adaptación distintas que, en un caso - $\mathrm{Pa}$ rranda - deslocalizan y modernizan la novela y universalizan a los personajes; y, en el otro - A esmorga - la búsqueda de fidelidad al texto es responsable de la belleza de la fotografía, de la credibilidad de lo contado, pero también de una simplificación de la estructura del mismo. Ahora bien, aunque los dos discursos fílmicos modifican, en mayor o menor medida, los marcos temporales, espaciales y enunciativos del hipotexto, ambos muestran al espectador la esencia de una novela compleja y excepcional: la tragedia de tres hombres que un día inician una huida hacia delante, un definitivo viaje sin retorno hacia la destrucción.

\section{Referencias}

Álvarez Patiño, Coral. La literatura y el cine a través de Eduardo Blanco Amor y Federico García Lorca. Salamanca: Universidad de Salamanca, 2018. http://hdl.handle. net/10366/139097

Blanco Amor, Eduardo. A Esmorga. (3ra. ed.). Vigo, España: Editorial Galaxia, 2010. 
Blanco Amor, Eduardo. La Parranda e outros guións inéditos. Coruña, España: Junta de Galicia y Centro Galego de Artes da Imax, 1994.

Bonet Mujica, Lluís. “"A Esmorga': viaje sin retorno". La Vanguardia. Web. 8 de mayo de 2015. https:/www.lavanguardia.com/cine/20150508/54430510391/a-esmorga-critica-de-cine.html

Cinema Ad Hoc. "Críticas: A Esmorga". Cinema Ad Hoc. Web. 6 de mayo de 2015. https:// cinemaadhoc.com/2015/05/criticas-a-esmorga/

Dasilva Fernández, Xosé Manuel. "As vicisitudes editoriais d'A Esmorga". Grial: Revista Galega de Cultura, núm, 148 (2009): 36-51.

Forcadela, Manuel. Guía de lectura de A esmorga de Eduardo Blanco Amor. Vigo, España: Edicións do Cumio, 1991. https://oximnasiodeacademo.files.wordpress. com/2012/05/guc3ada-de-lectura-de-a-esmorga-de-eduardo-blanco-amor.pdf

Gavilanes Laso, Xosé Luís: "Perfís estructurais de contido e expresión en A Esmorga". Grial: Revista Galega de Cultura, núm. 69 (1980): 286-289. Impreso.

Martínez Delgado, Ana Belén. A esmorga de Blanco Amor e Parranda de Gonzalo Suárez. Coruña, España: Ediciós do Castro, 2000.

Praza Pública. "Ignacio Vilar: 'a xente sae orgullosa de ver A Esmorga"". Praza Pública. Web. 1 de diciembre de 2014. https://praza.gal/cultura/ignacio-vilar-a-xente-sae-orgullosa-de-ver-a-esmorga

Reviriego, Carlos. “A Esmorga”. Sensacine. Web. Sin fecha. https://www.sensacine.com/pe$\underline{\text { liculas/pelicula-226627/sensacine/ }}$

----. “A esmorga (Ignacio Vilar)”. Caiman Cuadernos de Cine. Web. 8 de mayo de 2015. https://www.caimanediciones.es/a-esmorga-critica/

Rus Gascón, Pilar. Imaxe do mundo en Eduardo Blanco Amor. A muller, o conflicto social e os marxinados. Vigo: Edicións A Nosa Terra, 1997.

Sánchez Noriega, José Luís. De la literatura al cine. Teoría y análisis de la adaptación. Barcelona: Ediciones Paidós, 2000.

Sande, José Manuel. “Parranda, de Gonzalo Suárez”. El cine de Gonzalo Suárez. Ed. Carmen Becerra. España: Mirabel Editora, 2004, pp. 136-173.

Vázquez Souza, Ernesto y Xosé María Dorrabo Paz. "De $A$ Esmorga, texto literario, a Parranda, texto fílmico". Literatura y cine: perspectivas semióticas: actas del I Sim- 
posio de la Asociación Galega de Semiótica. Ed. Carlos J. Gómez Blanco. Coruña, España: Universidad de Coruña, 1997, pp. 145-164. http://hdl.handle.net/2183/9584

Vilar, Ignacio. "Entrevistas: Ignacio Vilar". Cinema Ad Hoc. Web. 10 de septiembre de 2015. https://cinemaadhoc.com/2015/05/entrevistas-ignacio-vilar/ 